\title{
Periodontal conditions of teeth presenting pathologic migration
}

\section{Condições periodontais de dentes com migração dentária patológica}

\author{
Maurício Ribeiro Costa* \\ Karina Gonzales Silvério* \\ Carlos Rossa Júnior** \\ Joni Augusto Cirelli**
}

\begin{abstract}
The aim of the present study was to evaluate the periodontal conditions of anterior teeth that presented pathologic migration in patients with chronic periodontitis and to compare periodontal destruction in migrated versus non-migrated teeth. The sample included 32 patients of both sexes (mean age: $46.0 \pm 11.6$ years) diagnosed with generalized chronic periodontitis and selected on the basis of the presence of pathologic migration in one or more anterior teeth. This migration was classified according to the following categories: facial flaring, diastema, proximal tilting, rotation or extrusion. The periodontal parameters recorded were clinical attachment loss (CAL) and percentage of radiographic bone loss (BL). Mean CAL of $5.50 \pm 2.20 \mathrm{~mm}$ and mean BL of $41.90 \pm 15.40 \%$ were found in 115 teeth assessed. The most frequent type of migration was facial flaring (34.80\%), followed by diastema $(27.00 \%)$. Extrusion was hardly observed in the sample $(4.30 \%)$. However, greater severity of BL and CAL were observed in teeth with this type of migration $(59.44 \%$ and $8.42 \mathrm{~mm}$, respectively), and in teeth with facial flaring $(45.17 \%$ of BL and $6.07 \mathrm{~mm}$ of CAL). Kruskal-Wallis test indicated that BL presented by teeth with extrusion or facial flaring was greater than that observed in rotated or tilted teeth $(p<0.05)$, while there was no difference between groups regarding CAL $(\mathrm{p}=0.11)$. It was observed that anterior teeth with pathologic migration presented greater CAL and BL (5.1 mm and 40\%) than non-migrated teeth (4.1 and 31\%). The study indicated that the most prevalent kind of pathologic migration is facial flaring, which was associated to higher level of bone loss.
\end{abstract}

DESCRIPTORS: Tooth migration; Periodontal attachment loss; Alveolar bone loss.

RESUMO: O objetivo deste estudo foi avaliar as condições clínicas periodontais de dentes anteriores com migração patológica (MDP) em pacientes com periodontite crônica generalizada e comparar a severidade de destruição periodontal entre dentes migrados e não-migrados. Foram selecionados 32 pacientes, de ambos os sexos, apresentando média de idade de 46,0 anos $( \pm 11,6)$, com perda clínica de inserção em dentes anteriores e presença de algum tipo de MDP, a saber: vestibularização, diastema, inclinação proximal, giroversão ou extrusão. Os parâmetros avaliados foram a perda clínica de inserção (PIC) e o percentual de perda óssea radiográfica (PO). Os resultados mostraram, em média, uma PIC de $5,50 \mathrm{~mm}( \pm 2,20 \mathrm{~mm})$ e uma PO de 41,90\% $( \pm 15,40 \%)$ do comprimento radicular, em 115 dentes selecionados. Os tipos mais freqüentes de migração foram vestibularização (34,80\%) e presença de diastemas $(27,00 \%)$. A extrusão foi a menos freqüente $(4,30 \%)$. Maiores valores de PO e PIC foram registrados nos dentes com extrusão $(59,44 \%$ e $8,42 \mathrm{~mm})$ e vestibularização $(45,17 \%$ e 6,07 mm). Esses valores de PO foram superiores aos observados nos dentes com giroversão ou inclinação proximal ( $p<0,05-$ Kruskal-Wallis). A PIC não apresentou diferenças significativas entre os diferentes tipos de migração $(p=0,11)$. Constatou-se que os dentes anteriores com MDP apresentaram maior PIC e PO (5,1 mm e 40\%) quando comparados aos não-migrados $(4,1 \mathrm{~mm}$ e $31 \%$ ). Pôde-se concluir também que o tipo de MDP mais prevalente foi a vestibularização, que esteve relacionada a maiores níveis de perda óssea.

DESCRITORES: Migração de dente; Perda da inserção periodontal; Perda óssea alveolar.

\section{INTRODUCTION}

The position of teeth in the dental arch depends on the health and height of the periodontium and on the forces exerted upon the tooth, mainly occlusion and pressure of lips, cheeks and tongue. The alteration of any of these factors pro- vokes a sequence of interrelated changes in the environment of a single tooth or of a group of teeth that results in pathological migration. Therefore, pathological tooth migration (PTM) can be defined as tooth displacement that occurs when the bal-

\footnotetext{
*Graduate Students; **Professors - Department of Periodontology, School of Dentistry of Araraquara, State University of São Paulo.
} 
Costa MR, Silvério KG, Rossa Júnior C, Cirelli JA. Periodontal conditions of teeth presenting pathologic migration. Braz Oral Res 2004;18(4):301-5.

ance among the factors which maintain physiologic tooth position is disturbed by periodontal disease.

The etiology of PTM is complex and multifactorial. A wide variety of factors such as periodontal attachment loss ${ }^{1,9}$, occlusal factors ${ }^{1}$, habits, pressure of granulomatous tissue of the infrabony periodontal pockets ${ }^{1,5,6}$, loss of posterior teeth ${ }^{1,3,4,6}$, lip frenula and gum hyperplasia caused by medications (phenytoin, cyclosporine and calcium channel blocking drugs) have been listed based on clinical observations. We can consider tooth grinding ${ }^{1,6,7}$, positioning of the tongue, lip habits (patients that bite their lips), suction and the habit of constantly having something in the mouth (e.g. pipe, pin, etc. $)^{8,13}$ some of the habits that are related to PTM.

Occurrence of PTM is high, reaching $56 \%$ in some studies ${ }^{8,13}$. This condition is more frequent in the anterior area ${ }^{1,8}$ and is usually the main complaint of periodontal patients, which motivates them to seek treatment. Several types of pathological migration, such as facial flaring, diastema, rotation and tilting can be found in one tooth or in a group of teeth ${ }^{8,13}$.

Because of its clinical importance, higher prevalence and direct relationship to periodontal attachment loss, new studies of PTM would be of great help to evaluate this condition. The objective of this research was to evaluate the occurrence of different kinds of PTM in anterior teeth in patients with generalized severe periodontitis in relation to the severity of periodontal destruction, and to compare the severity of periodontal destruction between anterior migrated teeth and non-migrated ones.

\section{MATERIAL AND METHODS Selection of patients}

Following the approval of this study by the Ethics and Research Committee of the School of Dentistry of Araraquara, State University of São Paulo, 32 patients were selected (37.6\% male and $62.4 \%$ female), with an average age of $46( \pm 11.6)$, from the periodontal clinic of the same school. The inclusion criteria involved:

- patients with generalized chronic periodontitis who noticed a change in the position of their anterior teeth over the last few years;

- patients who had not been periodontally treated in the last six months;
- patients who had at least 10 anterior teeth, with periodontal attachment loss in at least two of these teeth.

\section{Clinical examination}

The selected patients were submitted to complete periodontal examination including clinical attachment levels, probing pocket depth, and bleeding on probing, which confirmed the diagnosis of generalized chronic periodontitis. Clinical attachment level of the anterior teeth was recorded at six sites of each dental element: mesiobuccal, distobuccal, buccal, mesiolingual, distolingual and lingual. The presence and kind of PTM in anterior teeth and teeth loss were also evaluated.

\section{Radiographic evaluation}

After the examination, X-rays from the anterior teeth were taken. The technique used was the parallel one, with Ektaspeed film (Agfa-Gevaert Dentus M2 Comfort, Gevaert-Agfa NV, Amberes, Belgium) and Han-Shin positioners (Jon, São Paulo, Brazil). Proximal bone level was examined with a magnifying glass (CSR, mod. 5003, Guarulhos, SP, Brazil), a millimeter ruler (Acrimet, Ref. 511.0, São Bernardo do Campo, SP, Brazil) and an X-ray illuminator (Konex, mod. KO-NOPM, São Paulo, SP, Brazil). The following measurements were obtained:

- CO: the distance in millimeters from the cemento-enamel junction to the most coronary portion of the alveolar crest;

- CR: the distance in millimeters from the cemento-enamel junction to the apex of each tooth.

The percentage of proximal bone loss in each anterior tooth was evaluated and calculated using these two measurements.

\section{Data management and statistical analysis}

Kruskal-Wallis' statistical test was used to relate the different types of PTM to the severity of periodontal destruction using the radiographic (bone loss) and clinical parameters of attachment level. Due to the variation on migration that occurred in each patient, individual clinical parameters of every tooth were considered. Similarly, the loss of posterior teeth was also recorded in relation to the different types of PTM. The comparison of the severity of periodontal destruction between anterior migrating teeth and non-migrating teeth 
Costa MR, Silvério KG, Rossa Júnior C, Cirelli JA. Periodontal conditions of teeth presenting pathologic migration. Braz Oral Res 2004;18(4):301-5.

was done using the Wilcoxon test. The results were considered significant when $\mathrm{p}<0.05$.

\section{RESULTS}

One hundred and fifteen teeth of the 32 patients that participated in this study presented PTM. The results showed a mean CAL of $5.5 \pm 2.2 \mathrm{~mm}$ and mean BL of $41.9 \pm 15.4 \%$. All patients presented loss of posterior teeth $(6.09 \pm 4.12)$.

Graph 1 shows the predominance of the various kinds of pathological migration. The most frequent one was facial flaring $(34.80 \%)$, and extrusion was the least frequent one $(4.30 \%)$.

Table 1 shows the averages of attachment loss, percentages of bone loss and posterior teeth loss related to each kind of PTM. Higher percentages of alveolar bone loss and periodontal attachment loss were found in teeth with extrusion $(59.44 \pm 24.00 \%$ and $8.42 \pm 1.89 \mathrm{~mm}$ ) and with facial flaring $(45.17 \pm 14.10 \%$ and $6.07 \pm 1.97 \mathrm{~mm})$.

Table 2 shows that the amount of bone loss in teeth with extrusion or facial flaring was greater than that seen in teeth with rotation or proximal tilting ( $\mathrm{p}<0.05-$ Kruskal-Wallis). Clinical attachment loss ( $\mathrm{p}=0.11$ - Kruskal-Wallis) and posterior teeth loss ( $p=0.75-$ Kruskal-Wallis) were not significantly different regarding the different types of migration.

In a total of 346 anterior teeth, 115 were found with PTM. Graph 2 and Table 3 show the comparison of the severity of periodontal destruction between anterior migrated teeth and non-migrated ones in each patient. Anterior teeth with migration had a higher percentage of bone loss $(40 \%-\mathrm{p}=0.0008)$ and greater attachment loss $(5.1 \mathrm{~mm}-\mathrm{p}=0.0000)$ when compared to anterior non-migrated teeth ( $31 \%$ and $4.1 \mathrm{~mm})$.

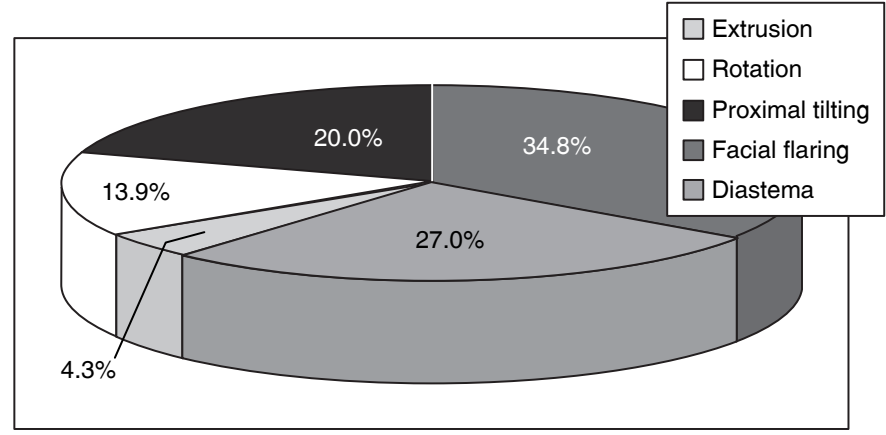

GRAPH 1 - Percentages of different kinds of pathologic tooth migration.

\section{DISCUSSION}

For this study, only patients who noticed shifting in the position of their teeth during the development of periodontal disease were considered PTM cases. During the clinical and radiographic exams, bone and clinical attachment loss were detected in different levels in at least one anterior tooth of each patient selected for the study. Although the combination of types of PTM in the 32 patients made it more difficult to identify the most prevalent form of migration, the results of this study are supported by Towfighi et al. ${ }^{13}$ (1997). In that study, facial flaring (90\%) and diastema (88.6\%) were recorded as the most frequent kinds of PTM observed in patients with moderate to severe periodontitis.

A few clinical studies, including renowned essays, have confirmed the idea that the destruction of periodontal attachment caused by periodontal disease is the main etiology of $\mathrm{PTM}^{2,10,11,13}$.

According to Carranza ${ }^{1}$ (1990), one reason for this is that occlusal forces considered normal become excessive to teeth with loss of supportive tissue and lead them to migration. Martinez-Canut et al. ${ }^{8}$ (1997) evaluated a sample of 852 periodontal patients and also observed that the main factor related to PTM was the loss of bone support, what

TABLE 1 - Prevalence (PREV), main clinical attachment loss (CAL), percentage of alveolar bone loss (BL) and loss of posterior teeth (LPT), according to the different kinds of pathologic tooth migration.

\begin{tabular}{l|c|c|c|c}
\hline \hline & PREV $(\%)$ & CAL $(\mathrm{mm})$ & BL $(\%)$ & LPT $(\mathrm{mm})$ \\
\hline Facial flaring & 34.80 & $6.07 \pm 1.97)$ & $45.17( \pm 14.10)$ & $6.47( \pm 4.95)$ \\
\hline Diastema & 27.00 & $5.32( \pm 1.95)$ & $38.35( \pm 10.46)$ & $6.09( \pm 4.52)$ \\
\hline Extrusion & 4.30 & $8.42 \pm 1.89)$ & $59.44( \pm 24.00)$ & $7.00( \pm 3.08)$ \\
\hline Rotation & 13.90 & $4.98( \pm 1.80)$ & $35.94( \pm 11.20)$ & $4.75( \pm 3.41)$ \\
\hline Proximal tilting & 20.00 & $4.89( \pm 2.51)$ & $36.63( \pm 16.33)$ & $6.17( \pm 4.43)$ \\
\hline \hline
\end{tabular}


Costa MR, Silvério KG, Rossa Júnior C, Cirelli JA. Periodontal conditions of teeth presenting pathologic migration. Braz Oral Res 2004;18(4):301-5.
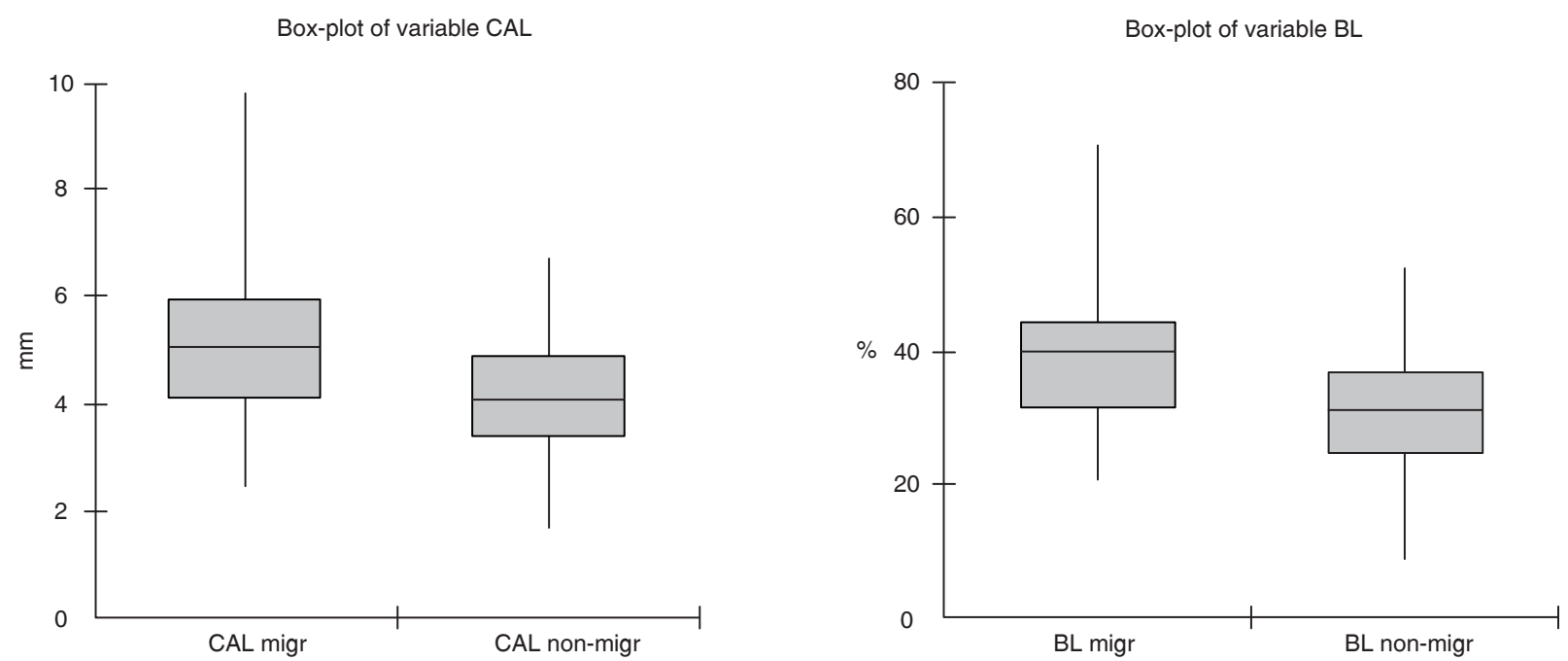

GRAPH 2 - Box-plot of comparative analysis for percentage of bone loss (BL) and attachment level (CAL) between migrated (migr) and non-migrated (non-migr) anterior teeth.

TABLE 2 - p values for multiple comparisons of alveolar bone loss observed with the different kinds of pathologic tooth migration.

\begin{tabular}{l|c|c|c|c}
\hline \hline & $\begin{array}{c}\text { Proximal } \\
\text { tilting }\end{array}$ & Rotation & Diastema & $\begin{array}{c}\text { Facial } \\
\text { flaring }\end{array}$ \\
\hline $\begin{array}{l}\text { Proximal } \\
\text { tilting }\end{array}$ & - & - & - & - \\
\hline Rotation & 0.93 & - & - & - \\
\hline Diastema & 0.14 & 0.21 & - & - \\
\hline $\begin{array}{l}\text { Facial } \\
\text { flaring }\end{array}$ & 0.02 & 0.04 & 0.36 & - \\
\hline Extrusion & 0.01 & 0.02 & 0.09 & 0.20 \\
\hline \hline
\end{tabular}

lead to tooth loss and gingival inflammation. Patients that presented an average bone loss of $25 \%$ were related to $33.6 \%$ of PTM, while those with bone loss between 50 and $75 \%$ corresponded to the group with predominance of PTM $(80 \%)$. Regarding tooth loss and gum inflammation, a higher prevalence of PTM (72\%) was seen in patients who had lost 3 or more teeth and patients with gingival index higher than 2 (59\%). These numbers corroborate the results of our research, which showed a correlation between some types of migration (facial flaring and extrusion) and higher percentages of X-rayed bone loss. The high rate of bone loss should be regarded with caution in cases of extrusion because a more coronary position determines
TABLE 3 - Use of Wilcoxon test for the variables bone loss and attachment loss.

\begin{tabular}{l|c|c|c|c}
\hline \hline Variables & $\mathrm{n}$ & $\begin{array}{c}\text { Mean } \\
\text { difference } \\
\text { (migrated - } \\
\text { non-migrated) }\end{array}$ & $\mathrm{Z}$ & $\mathrm{p}$ value \\
\hline Bone loss & 346 & 7.29 & -3.34 & 0.0008 \\
\hline $\begin{array}{l}\text { Attachment } \\
\text { loss }\end{array}$ & 346 & 1.07 & -4.27 & 0.0000 \\
\hline \hline
\end{tabular}

a larger distance between the alveolar crest and the cemento-enamel junction. Posterior tooth loss was also registered in this study, and it was observed in all patients $(6.09 \pm 4.12)$. The design of the present study did not allow us to determine the influence of this factor on PTM, but since it tends to result in overloading in the anterior teeth region, it can be seen as an important etiologic factor to PTM.

The results of this research regarding percentage of bone loss and loss of attachment in migrated and non-migrated teeth are in accordance with the values presented in the studies done by Selwyn ${ }^{12}$ (1973) and Towfighi et al. ${ }^{13}$ (1997). The former compared the level of radiographic bone loss using 30 patients with PTM in anterior teeth and 45 patients with periodontal disease, but without PTM (control group). He found that larger bone loss occurred in patients with PTM. The latter analyzed 75 pairs 
Costa MR, Silvério KG, Rossa Júnior C, Cirelli JA. Periodontal conditions of teeth presenting pathologic migration. Braz Oral Res 2004;18(4):301-5.

of homologous teeth. Each pair had a migrated and a non-migrated tooth. The average of attachment loss of migrated teeth $(4.79 \pm 0.28 \mathrm{~mm})$ was significantly larger than the average of non-migrated ones $(3.21 \pm 0.18 \mathrm{~mm})$ when Wilcoxon test was used with a significance level of $p<0.05$. In the present study, patients' anterior teeth were classified as migrated or non-migrated teeth and Wilcoxon test allowed the evaluation considering the patient as the unit of analysis. Considering the multifactorial nature of migrating teeth, the use of the same patient as control becomes important. It eliminates the individual factors that can influence the position of teeth. However, the variations related to each tooth such as occlusal forces, habit

\section{REFERENCES}

1. Carranza FA Jr. Occlusal trauma. In: Carranza FA Jr. Glickman's clinical periodontology. Philadelphia: Saunders; 1990. p. 284-306.

2. Gaumet PE, Brunsvold MI, McMahan CA. Spontaneous repositioning of pathologically migrated teeth. J Periodontol 1999;70:1177-84.

3. Giovanoli JL, Dersot JM. Posterior bite collapse. 1. Etiology and diagnosis. J Periodontol 1989;8:187-94.

4. Heckert L. Prerestorative therapy using a modified Hawley splint. J Prosthet Dent 1980;43:26-30.

5 . Hirschfeld I. The dynamic relationship between pathologically migration teeth and inflammatory tissue in periodontal pockets: a clinical study. J Periodontol 1933;4:35-47.

6. Hirschfeld I, Geiger A. Etiologic factors of tooth malposition. In: Hirschfeld L, Geiger A. Minor tooth movement in general practice. St. Louis: Mosby; 1974. p. 78-139.

7. Marks MH, Levitt HL. Etiology of adult tooth malposition. In: Marks MH, Corn H. Atlas of adult orthodontics. Philadelphia: Lea and Febiger; 1989. p. 57-8. influences, tooth size and periodontal conditions are the main limitations of this kind of study.

\section{CONCLUSIONS}

It was concluded that the most prevalent kind of pathologic migration in periodontal patients is facial flaring, which was associated to higher levels of bone loss. In addition, we found higher percentage of bone loss and greater attachment loss in anterior teeth with pathological migration when compared to non-migrated anterior teeth. Still considering the nature of PTM etiology, future studies should be carried out to analyze the influence of other individual factors such as occlusion and parafunctional habits.

8. Martinez-Canut P, Carrasquer A, Magán R, Lorca A. A study on factors associated with pathologic tooth migration. $\mathrm{J}$ Clin Periodontol 1997;24:492-7.

9. Melsen B. Limitations in adult orthodontics. In: Melsen B. Current controversies in orthodontics. Chicago: Quintessence Publishing; 1991. p. 147-80.

10. Ross IF. Endogenous tooth movement. J Am Dent Assoc 1990;60:738-46.

11. Ross IF. Tooth movement and repositioning of the mandible without appliances. J Prosthet Dent 1974;31:2906.

12. Selwyn SL. An assessment of patients with periodontally involved migrated incisors. J Dent 1973;31:153-7.

13. Towfighi PP, Brunsvold MA, Storey AT, Arnold RM, Willian DE, McMahan CA. Pathologic migration of anterior teeth in patients with moderate to severe periodontitis. J Periodontol 1997;68:967-72.

Received for publication on Apr 30, 2004

Sent for alterations on Oct 06, 2004 Accepted for publication on Dec 16, 2004 